\title{
Long-Term Survival After Stroke According to Reperfusion Therapy, Cardiovascular Therapy and Gender
}

\author{
Jose Luis Clua-Espuny, b, h, Sonia Abilleirac ${ }^{\mathrm{c}}$, Lluisa Queralt-Tomas ${ }^{\mathrm{d}}$, \\ Antonia Gonzalez-Henares ${ }^{\mathrm{b}, \mathrm{e}}$, Vicente Gil-Guillen ${ }^{\mathrm{f}}$, \\ Eulalia Muria-Subirats ${ }^{\mathrm{g}}$, Juan Ballesta-Ors ${ }^{\mathrm{g}}$
}

\begin{abstract}
Background: A wide variety of factors influence stroke prognosis, including age, stroke severity and comorbid conditions; but most current information about outcomes and safety is derived from patients at $3-12$ months and mostly coming from the hospital activity. The aim of this study is to evaluate whether treatment strategies have a differential impact on long-survival after acute ischemic stroke among men versus women.
\end{abstract}

Methods: Acute ischemic stroke patients identified from the population-based register between January 1, 2011 and December 31, 2012 were included, and they were classified into: 1) Acute ischemic stroke + intravenous thrombolysis (group I); 2) Acute ischemic stroke + mechanical thrombectomy with or without intravenous thrombolysis (group II); 3) Acute ischemic stroke + medical therapy alone (no reperfusion therapies) (group III). Follow-up went through up until December 2016. The probability of survival was estimated by the Kaplan-Meier method, and the hazard ratio was obtained by using the

Manuscript submitted January 31, 2019, accepted March 16, 2019

aEAP-Tortosa 1-Est, Catalonian Health Institute, SAP Terres de l'Ebre, Health Department, Generalitat de Catalunya, CAP Temple, 43500 Tortosa, Spain bDepartment of Research, ICS Terres de l'Ebre, Research Institute University Primary Care (IDIAP) Jordi Gol, Barcelona, Spain

'Stroke Programme, Agency for Health Quality and Assessment of Catalonia, CIBER Epidemiologia y Salud Publica (CIBERESP), Edifici Salvany, Roc Boronat 81-95, 2a planta 08005, Barcelona, Spain

dEAP-Tortosa-2-Oest, Catalonian Health Institute, SAP Terres de l'Ebre, Health Department, Generalitat de Catalunya, CAP Xerta, Barcelona, 43592 Catalonia, Spain

eEAP-Alcanar-St Carlos de la Rapita, Catalonian Health Institute, SAP Terres de l'Ebre, Health Department, Generalitat de Catalunya, CAP St Carles de la Rapita, 43540, Spain

${ }^{\mathrm{f}}$ Clinical Evidence Based Medicine and Emotional Department, Miguel Hernandez University, Family and Community Specialty, Crta. Nacional, N-332 s/n, 03550 Sant Joan (Alicante), Spain

gUUDD Tortosa-Terres de l'Ebre, Catalonian Health Institute, SAP Terres de l'Ebre, Health Department, Generalitat de Catalunya, CAP Temple, 43500 Tortosa, Spain

${ }^{\mathrm{h}}$ Corresponding Author: Jose Luis Clua-Espuny, EAP-Tortosa Est, Health Catalonian Institute, SAP Terres de 1'Ebre, Health Department, Generalitat de Catalunya, Placa Carrilet, s/num Tortosa 43500, Spain.

Email: jlclua@telefonica.net

doi: https://doi.org/10.14740/cr839
Cox proportional hazard regression models. Mortality was interpreted as overall mortality.

Results: A total of 14,368 cases (men $50.1 \%$ ), $77.1 \pm 11.0$ years old were included. There was higher survival among those treated with intravenous thrombolysis $(\mathrm{P}<0.001)$; women treated with thrombectomy $(\mathrm{P}<0.001)$; and women $<80$ years old without reperfusion therapy. The most common medications were antiplatelets $(52.8 \%)$, associated with lower survival ( $\mathrm{P}<0.001)$; and statins $(46.5 \%)$, associated with higher survival. The regression model produced the following independent outcome variables associated to mortality: anticoagulant hazard ratio (HR) 1.53 (95\% confidence interval $(95 \% \mathrm{CI})$ : 1.44 - 1.63, $\mathrm{P}<0.001)$, diuretics HR 1.71 (95\% CI: 1.63 - 1.79, $\mathrm{P}<$ 0.001 ), antiplatelet HR 1.49 (95\% CI: $1.42-1.56, \mathrm{P}<0.001)$, statins HR 0.73 (95\% CI: $0.70-0.77$; P $<0.001)$, angiotensin II receptor antagonists HR 0.93 (95\% CI: $0.89-0.98, \mathrm{P}=0.008)$ and reperfusion therapy HR $0.88(95 \% \mathrm{CI}: 0.81-0.97, \mathrm{P}=0.009)$.

Conclusions: Men and women have different prognoses after revascularization treatment for acute ischemic stroke. Under 80 years old the women appear to have a better outcome than men when treated with thrombolysis therapy and/or catheter-based thrombectomy. The chronic cardiovascular pharmacotherapy must be evaluated whether they should be included as factors in the decision to reperfusion.

Keywords: Acute ischemic stroke; Revascularization therapy; Sex; Chronic comorbidities; Long-term survival

\section{Introduction}

A wide variety of factors influence stroke prognosis, including age, stroke severity and comorbid conditions [1-4]. In addition, interventions such as reperfusion therapy can play a major role in the outcome of ischemic stroke. Previous reports [5-10] concerning sex differences in stroke $[7,11,12]$ and outcome are inconsistent $[13,14]$ and are sometimes difficult to interpret; and the reasons for disparities remain unclear despite adjustment for baseline differences in age, prestroke function and comorbidities. Actually most current information about outcomes and safety is derived from patients at $3-12$ months, and mostly coming from the hospital activity that are not avail- 
able in the area of primary care. There is neither study assessing the efficacy of revascularization (medical therapy alone vs. intravenous thrombolysis (IVT) vs. mechanical thrombectomy) in long-term outcome beyond hospital discharge, nor evaluation of potential effects on survival from interactions of cardiovascular chronic treatments and revascularization therapy associated with gender differences.

This work is a continuation and extension of the Ebrictus study [15-17]. The aim of our study was to evaluate whether treatment strategies have a differential impact on long-term survival after acute ischemic stroke (AIS) among men versus women.

\section{Materials and Methods}

\section{Data collection and study procedures}

This cohort study is based on AIS patients identified from the Minimum Basic Data Register (MBDR) at hospital discharge through specific International Classification of Diseases (ICD9) codes. Access to population-based data was reached through the Public Program epidemiological analysis for Health Research and Innovation in Catalonia (PADRIS). The measures were collected by a retrospective review of medical records of consecutive stroke admissions (January 1, 2011 through December 31, 2012) in Catalonia, Spain. Eligible patients were between the ages of 15 and 90 years. The study protocol, which is available at "Long survival after ischemic stroke and thrombolysis in Catalonia", ClinicalTrials.gov number, NCT03247036, and has been certified by the Independent Ethics Committee (IEC) of University Institute for Primary Care Research Jordi Gol (IDIAP), code 4R17/017.

The primary outcome was all-causes mortality. The study complies with the Helsinki Declaration and the local ethics committee requirements for clinical research; and the Institutional Review Board Approval.

\section{Case definition}

The automated operation of the PADRIS database retrieved all patients with a diagnosis code of AIS (codes 433.x1, 434.xx, and 436) with and without any of the following procedures codes: 99.10 "Injection or infusion of thrombolytic agent", 39.74 "Endovascular removal of obstruction from head and neck vessel(s)", and 38.91 "Arterial catheterization". According to ICD-9 procedure codes, the cohort was classified into: 1) AIS + IVT (group I); 2) AIS + mechanical thrombectomy with or without IVT (group II); and 3) AIS + medical therapy alone (no reperfusion therapies) (group III). An external audit was carried out on the general information and to investigate irregularities in the inclusion criteria.

The variables collected included: date of hospital admission, date of discharge, age, gender, treatment group (I, II or III), medication dispensation from the Integral System of Electronic Prescription (ISEP) from at least 3 months before episode (anticoagulant, antiplatelets, statin, antidiabetics, diu- retics, angiotensin converting enzyme inhibitor, angiotensin II receptor antagonists (A-IIRA), and beta-blocker); and patient vital status (alive/dead), and date (day/month/year) of death from the Central Register of insured people (CRA). All these registries are population-based and managed by the Health Department, Government of Catalonia.

\section{Statistical analysis}

Statistical analysis was undertaken with the following: 1) Descriptive study of basic statistics and standard deviation of key variables stratified by age and sex; 2) The probability of survival was estimated by the Kaplan-Meier method, and the hazard ratio (HR) was obtained by using the Cox proportional hazard regression models. Mortality was interpreted as overall mortality. The variables were included in a multivariate model performed with adjustment for age, sex, and type of medication. The analysis and processing of data were performed using the SPSS 11.5 statistical package for Windows.

\section{Results}

\section{Characteristics of the study population}

A total of 14,368 AIS patients were included (men 50.1\%). Table 1 shows the baseline demographics and cardiovascular medication used. The average patient age was $77.1 \pm 11.0$ years and average follow-up was $3.1 \pm 2.2$ years. Men (74.2 $\pm 11.1)$ were significantly younger $(\mathrm{P}<0.001)$ than women $(80.0 \pm 10.2)$. The most commonly medications (Table 2$)$ were antiplatelets $(52.8 \%)$ associated with lower survival outcome $(\mathrm{P}<0.001)$, and statins $(46.5 \%)$, associated with higher survival outcome, independent of gender. Between the ages of 60 and 79 years, the most prescribed medications included anticoagulants (13.5-15.3\%), antidiabetics (34-37.6\%), statins (54.5-55.7\%), diuretics (54.8\%) and antiplatelets prescriptions which increased progressively from $44.4 \%$ at $<60$ years to $63.4 \%$ at $>90$ years.

\section{Mortality rates}

Overall, all-causes mortality was $43.8 \%$, increasing from $17.1 \%<60$ years up to $93.5 \%>90$ years (Fig. 1). The cumulative 5-year survival proportion was $0.30 \pm 0.06$ among women and $0.38 \pm 0.02$ among men $(\mathrm{P}<0.001)$ after stroke. The revascularization procedure was associated to different outcome (Fig. 2). The multivariate regression model identified the following independent outcome variables: anticoagulant HR 1.53 (95\% CI:1.44 - 1.63, P < 0.001), diuretics HR 1.71 (95\% CI: $1.63-1.79, \mathrm{P}<0.001)$, antiplatelets HR $1.49(95 \%$ CI: $1.42-1.56, \mathrm{P}<0.001)$, statins HR 0.73 (95\% CI: 0.70 $0.77, \mathrm{P}<0.001)$, A-IIRA HR 0.93 (95\% CI: $0.89-0.98, \mathrm{P}=$ $0.008)$ and reperfusion therapy HR 0.88 (95\% CI: $0.81-0.97$, $\mathrm{P}=0.009$ ).

There were 941 patients (471 women) received IVT (group 

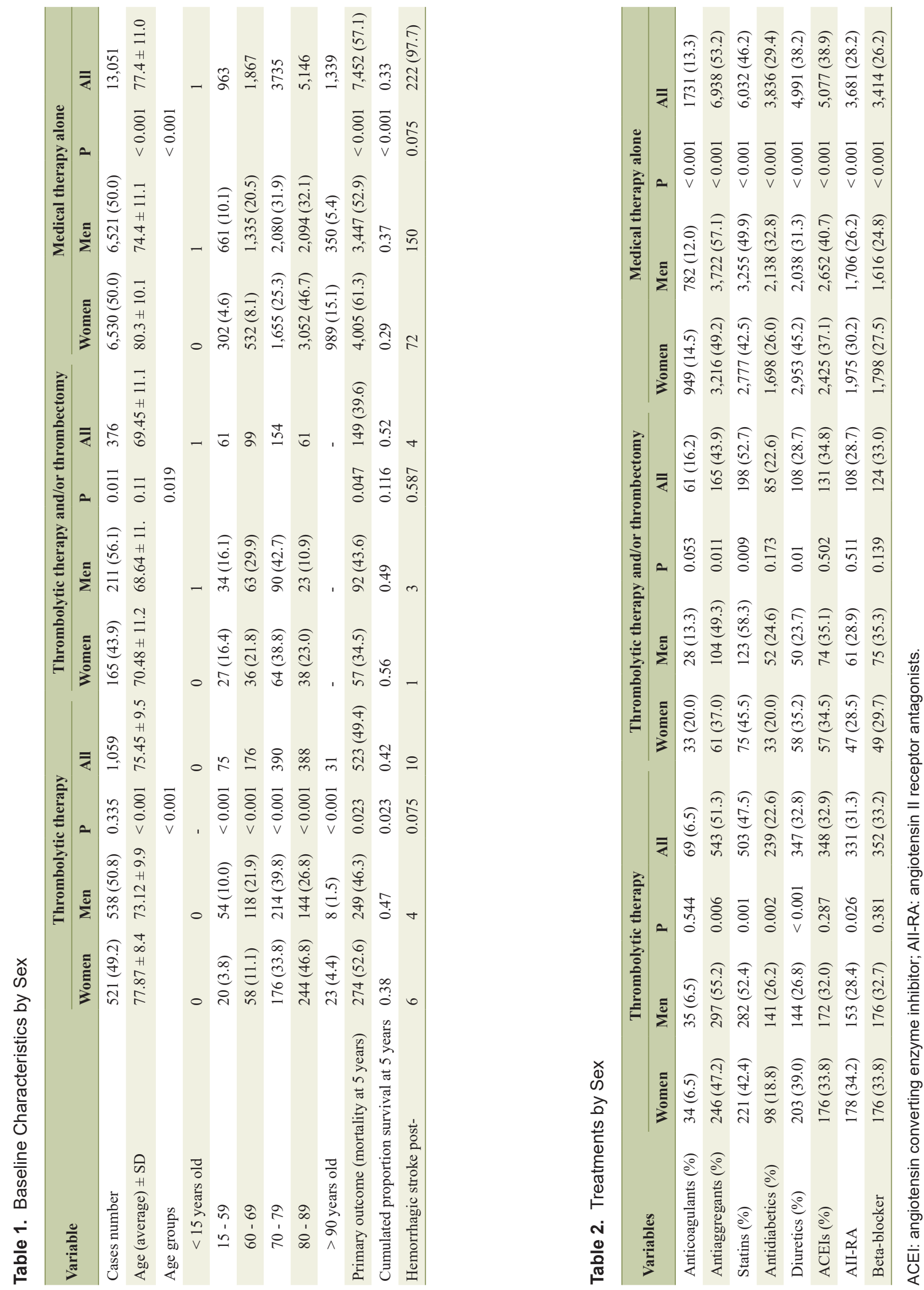


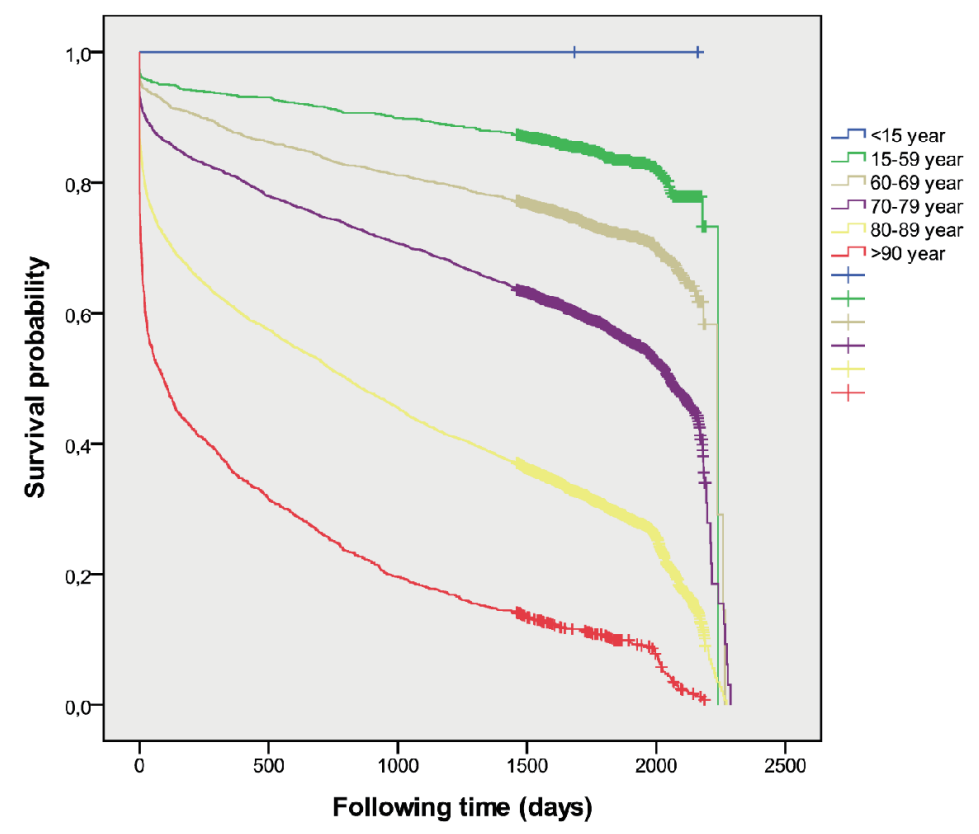

Figure 1. Overall mortality according to age (all cases).

I) and had better survival than those who did not receive it ( $\mathrm{P}$ $=0.001)$ with an adjusted HR $0.83(0.764-0.913)$ at 5 -year survival, higher among men $(\mathrm{P}=0.02)$ (Fig. 3). Women were older than men $(78.4 \pm 8.2$ vs. $73.4 \pm 10.0, \mathrm{P}<0.001)$. A higher mortality was shown among those treated with diuretics $(\mathrm{P}<$ $0.001)$ and/or antiplatelets $(P=0.001)$ independent of gender. The multivariate regression model identified the following independent outcome variables: age HR 1.08 (95\% CI: 1.06 1.09, $\mathrm{P}=0.001)$, diuretics HR 1.34 (95\% CI: $1.12-1.61, \mathrm{P}<$ 0.001 ), antiplatelets HR 1.34 (95\% CI: $1.12-1.60, \mathrm{P}<0.001)$, anticoagulant HR $1.43(95 \% \mathrm{CI}: 1.03-2.00, \mathrm{P}=0.03)$ and antidiabetics HR 1.24 (95\% CI: $1.02-1.52, \mathrm{P}=0.03)$. Of the 376 cases who were treated with thrombolysis therapy and/or catheter-based thrombectomy (group II) the number was significantly higher among men $(\mathrm{P}=0.01)$, but resulted in better survival outcomes among women $(\mathrm{P}=0.05)$ (Fig. 4) than men, and got the best survival profile among women $(\mathrm{P}<0.001)$ (Figs. 5, 6).

Totally, $13,051(90.8 \%$ patients, women $50.0 \%)$ were treated with medical therapy alone (group III). They were significantly older than those with reperfusion therapy (77.4 \pm 11.1 vs. $75.9 \pm 9.5, \mathrm{P}<0.001)$; and women were signifi-

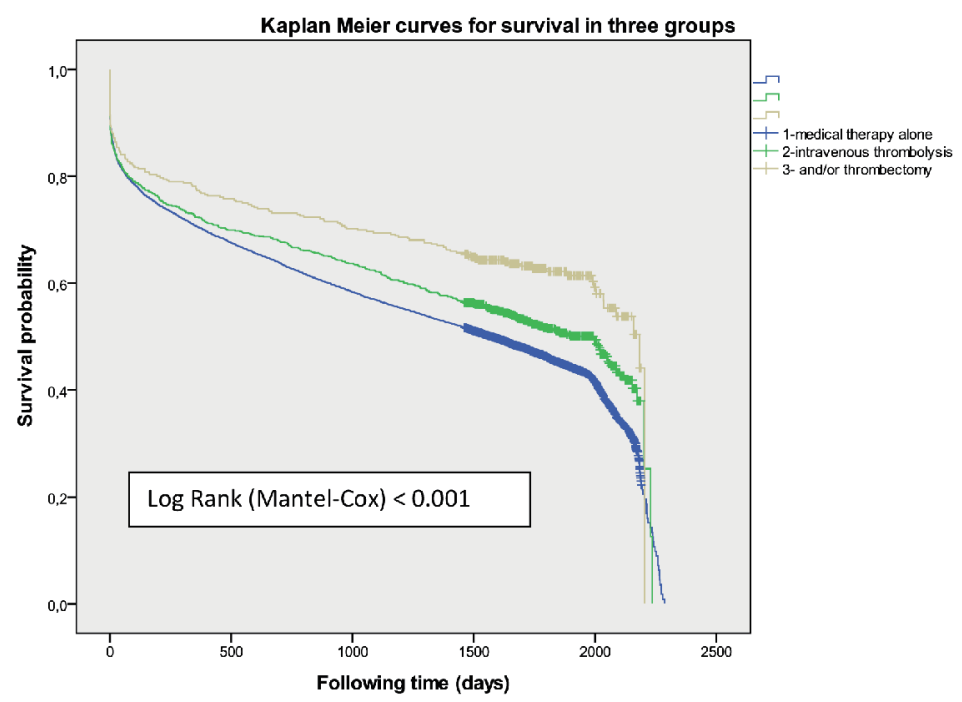

Figure 2. Overall mortality according to revascularization procedure (all cases). 


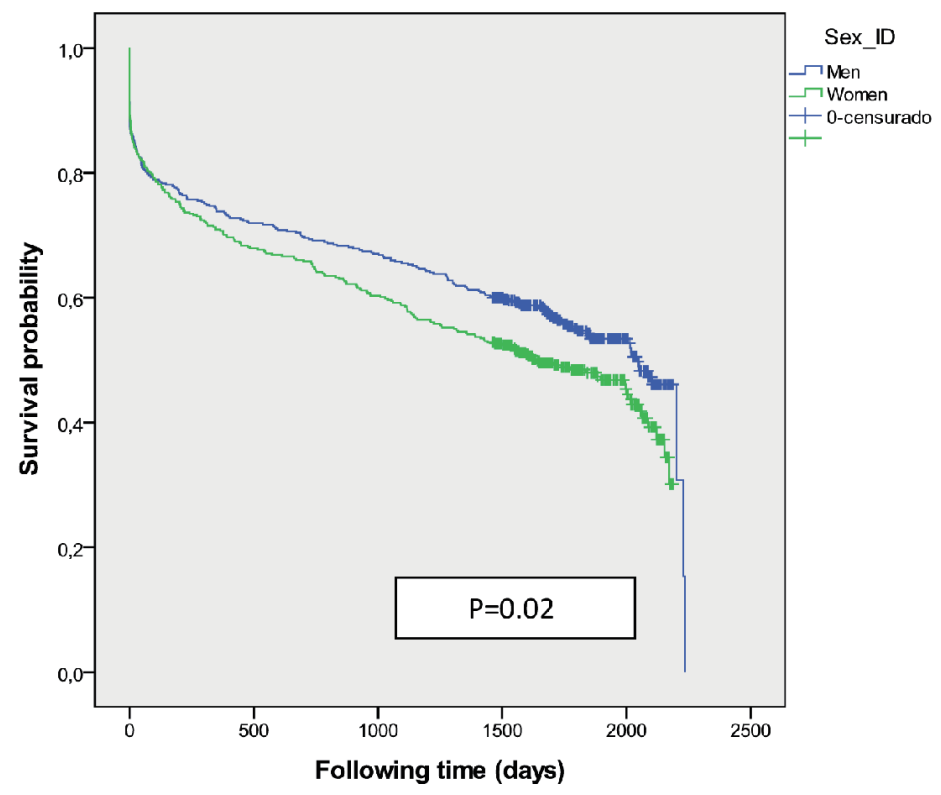

Figure 3. Survival probability for medical therapy including intravenous thrombolysis (group I) according to sex.

cantly older than men $(\mathrm{P}<0.001)(80.3 \pm 10.1$ vs. $74.4 \pm$ 11.1). Overall, there was higher survival $(\mathrm{P}<0.001)$ among women under 80 years. The overall survival probability was $0.29 \pm 0.08$ among women and $0.37 \pm 0.06$ among men $(\mathrm{P}$ $<0.001) 5$ years after stroke. Mortality was higher among those treated with anticoagulants $(\mathrm{P}<0.001)$, diuretics $(\mathrm{P}<$ $0.001)$, antiplatelets $(\mathrm{P}<0.001)$ and beta-blockers $(\mathrm{P}=0.02)$; but the survival was significantly longer if patients were treated with A-IIRA $(\mathrm{P}<0.001)$, antidiabetics $(\mathrm{P}<0.001)$ and statins $(\mathrm{P}<0.001)$ without differences by gender. The beta-blockers resulted in better survival outcomes in women and the antidiabetics in men $(\mathrm{P}<0.001)$. The multivariate regression model identified the following independent outcome variables: A-IIRA HR 0.89 (95\% CI: $0.82-0.96, \mathrm{P}=0.005)$, statins HR 0.90 (95\% CI: $0.84-0.96, \mathrm{P}=0.003)$, diuretics HR 1.48 (95\% CI: $1.38-1.59, \mathrm{P}<0.001)$, anticoagulant HR 1.32 (95\% CI: $1.20-1.47, \mathrm{P}<0.001)$, antiplatelets HR 1.16 (95\% CI: $1.08-1.25, \mathrm{P}<0.001)$ and age HR $1.1(95 \% \mathrm{CI}$ :

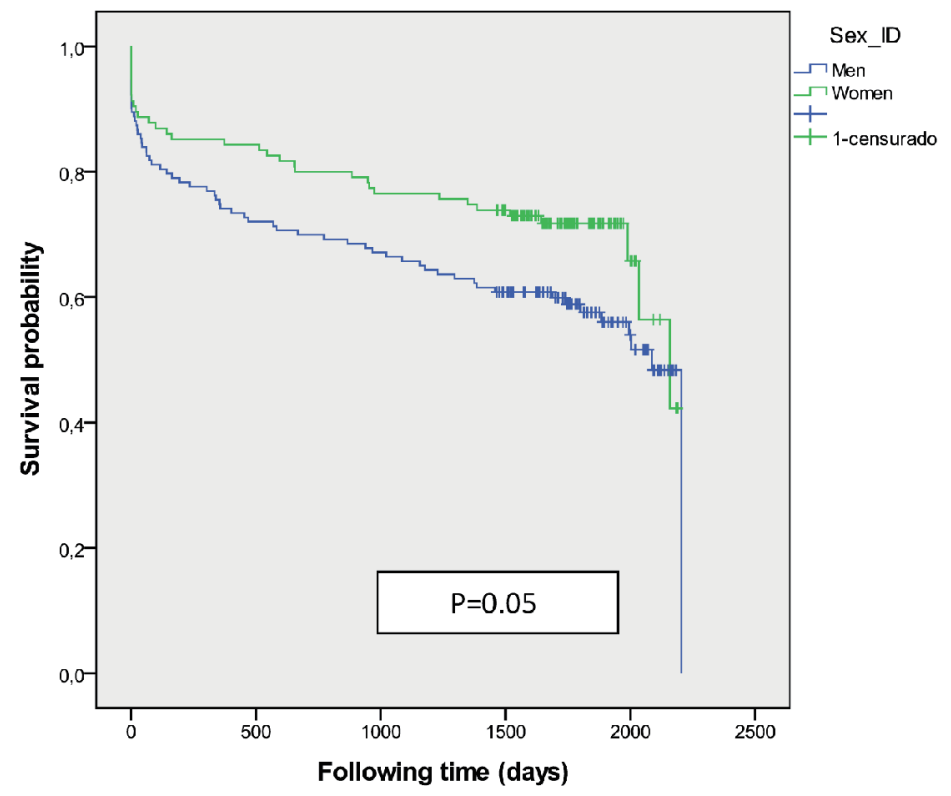

Figure 4. Survival curve for mechanical thrombectomy with or without intravenous thrombolysis (group II) according to sex. 


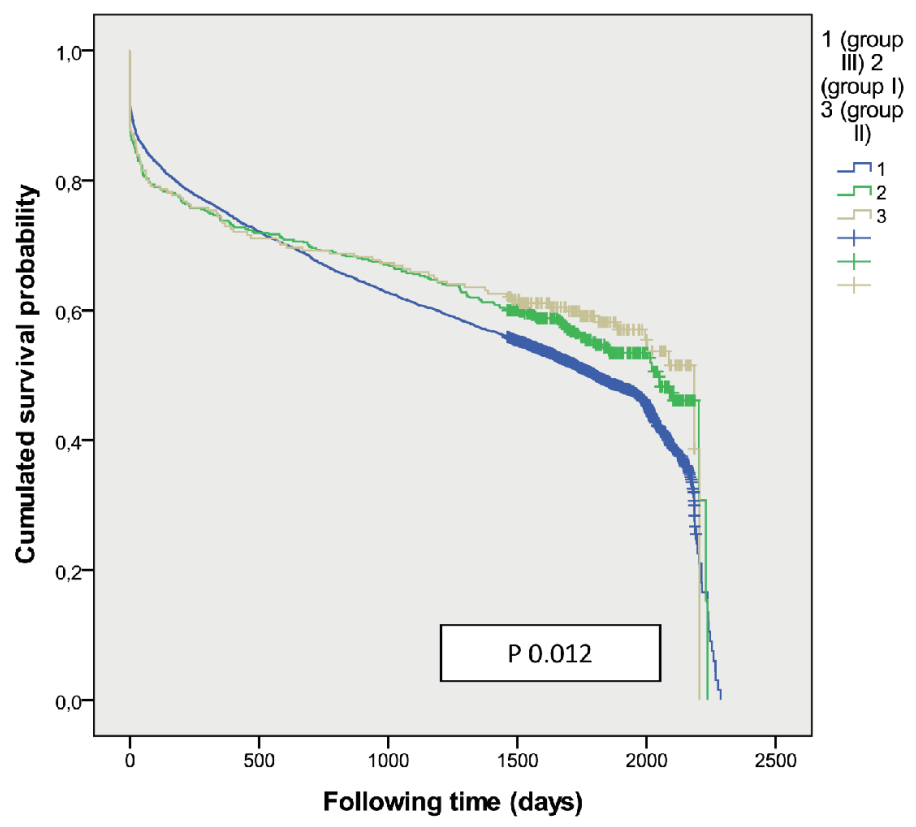

Figure 5. Overall mortality according treatment group in men.

$1.06-1.07, \mathrm{P}<0.001)$.

\section{Discussion}

This study brings results that reperfusion therapy seems to benefit women and men differently. We observed the following key findings: 1) IVT modifies the long-term survival expected in the natural course after AIS; 2) Women were significantly older in the group treated with medical therapy alone, but their survival was better than that of men over 80 years old; 3 ) Some medications/drugs could be associated with a bad prognosis,

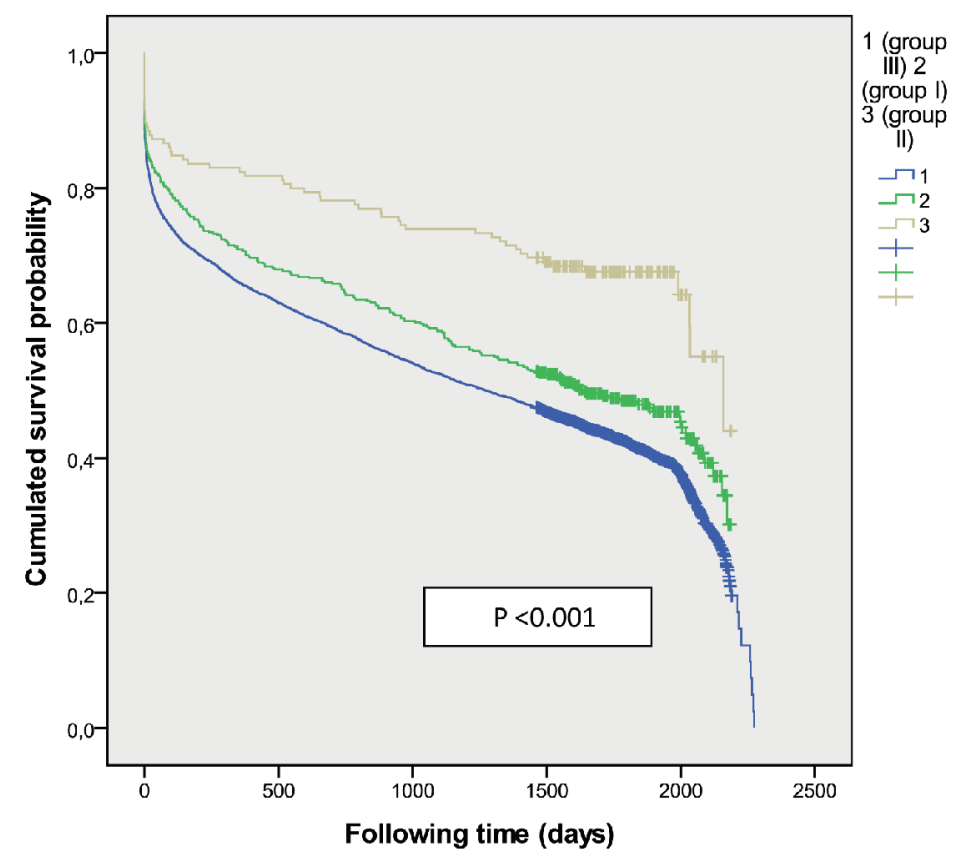

Figure 6. Overall mortality according treatment group in women. 
and their use could be an indicator of that prognosis; 4) Women tend to be undertreated with medical therapies which is consistent with data from the cardiovascular outcomes literature; 5) Women in the group of mechanical thrombectomy with or without IVT showed better survival than men although our sample size was not sufficient to permit robust assessments.

Some authors [18] have suggested that these differences are multifactorial, but new data suggest that there are biological differences [19]. The challenge is whether these data can achieve better health outcomes through the selection of patients with a more favorable risk versus selection on the basis of reperfusion profile.

A greater understanding of the differences and similarities between males and females with respect to previous cardiovascular risk factors $[1,17,18,20]$, previous physical or mental condition $[21,22]$, response to acute stroke therapies, and recovery will hopefully lead to better outcomes in the future.

The chronic cardiovascular medications used confirm epidemiological data of stroke-related risk factors and comorbid conditions in Catalonia [4], highlighting that a higher percentage of men have been treated with antiplatelets $(P=0.006)$, statins $(\mathrm{P}=0.001)$ and antidiabetics $(\mathrm{P}=0.002)$, apparently for more ischemic comorbidities; and a higher percentage of women took AII-RA $(\mathrm{P}=0.026)$ and diuretics $(\mathrm{P}<0.001)$ possibly indicating a higher proportion of heart failure in that population. Possibly, the increase of mortality that is associated with cardiovascular pharmacotherapy is actually related to the basal comorbidities treated as diabetes mellitus, hypertension, heart failure, coronary artery diseases and/or atrial fibrillation. These comorbidities must be evaluated to determine their effects on the reperfusion therapy outcome and whether they should be included as factors in the decision to reperfusion [23].

The protective effects of statins and ARA-II are clearly independent of treatment with reperfusion therapy or the absence thereof. Statin use is widely delivered in patients who have previously suffered a stroke and were significantly more likely to survive compared with non-users [24, 25]. Aspirin given together with a thrombolytic agent may worsen the risk-to-benefit ratio [26] probably due to cerebral hemorrhagic complications, but this problem was not investigated in our study. The anticoagulant treatment often has poor quality results and has been associated with high frequency of complications and poor outcome; but in selected new oral anticoagulants (NOACs) treated patients with an acute stroke, endovascular thrombectomy is preferred if indicated and possible [27]. The use of antidiabetics was associated with higher survival in the group I, differing with results [1] that showed higher death rates among women, and higher long-term mortality in patients with diabetes [28]. Although diabetes is not a contraindication for thrombolysis therapy, patients with diabetes are often undertreated [29] and could have a sampling bias.

Previous clinical trials have largely ignored the potential for gender-specific responses to treatments [30, 31]. It may be that the beneficial impact of reperfusion therapy could be neutralized by basal comorbidities and/or their treatment, or perhaps the mortality outcome of the reperfusion therapy depends more on the comorbidities profile. The group with thrombectomy was the only one in which women had more favorable outcomes than men, but also more men than women received mechanical thrombectomy. This fact is interesting to point out for future study. The development of computerized decision tools $[32,33]$ that examine factors such as age, gender, cardiovascular comorbidities and their treatment may support the optimization of decision making to further improve mechanical thrombectomy effectiveness as standard care for eligible patients [34] and seamlessly support different approaches to decision-making about reperfusion therapy. Eventually, the results of controlled trials [2, 35-38] have confirmed the safety and efficacy of mechanical thrombectomy and its importance for the advancement of stroke care [39], but have not been evaluated different effects by gender and comorbidities.

There are some limitations to our study. First, it consisted of a retrospective review of medical records. Primary randomization of gender is not possible. It was not possible divide the group mechanical thrombectomy with or without IVT by reason of codification methodology. The results were limited to patients treated with reperfusion therapy and drugs for management of chronic conditions. The accessibility to procedure includes variations between different areas, and the type and quality of revascularization that patients can access often will depend on where they live particularly in the rural and remote areas.

\section{Conclusions}

Men and women have different prognoses after revascularization treatment for AIS. Under 80 years old the women appear to have a better outcome than men when treated with thrombolysis therapy and/or catheter-based thrombectomy and with medical therapy alone; whereas the men appear to have a better outcome than women when received just IVT. The chronic cardiovascular pharmacotherapy must be evaluated to determine its effects on the reperfusion therapy outcome and whether they should be included as factors in the decision to reperfusion.

\section{Acknowledgments}

The authors wish to thank the research group Ebrictus for providing assistance and support to this manuscript; as well this study has been made using the "Programa public d'Analitica de Dades per a la Recerca I la Innovacio en Salut a Catalunya - PADRIS by Carles Rubies I Feijoo for his technical support from AQUAS (Agencia de Qualitat I Avaluacio Sanitaries de Catalunya).

\section{Financial Disclosure or Funding}

No funding or sponsorship was received for this study or publication of this article.

\section{Conflict of Interest}

All authors declare that they have no conflict of interest. 


\section{Author Contributions}

Authors whose names appear on the submission have contributed sufficiently to the scientific work and therefore share collective responsibility and accountability for the results.

\section{Disclosures}

The abstract of this paper was presented at the fourth European Stroke Organisation Conference as a poster presentation with interim findings. The poster's abstract was published in "Poster Abstracts" in European Stroke Organisation Conference (2018): Abstracts (https://journals.sagepub.com/doi/ full/10.1177/2396987318770127).

\section{Abbreviations}

AIS: acute ischemic stroke; IVT: intravenous thrombolysis; MBDR: Minimum Basic Data Register at hospital discharge; ICD-9: International Classification of Diseases; PADRIS: Public Program epidemiological analysis for Health Research and Innovation in Catalonia; IEC: Independent Ethics Committee; IDIAP: University Institute for Primary Care Research Jordi Gol; ISEP: Integral System of Electronic Prescription; CRI: Central Register of insured population; HR: hazard ratio; AIIRA: angiotensin II receptor antagonist; NOAC: new oral anticoagulant; SD: standard deviation

\section{References}

1. Eriksson M, Carlberg B, Eliasson M. The disparity in long-term survival after a first stroke in patients with and without diabetes persists: the Northern Sweden MONICA study. Cerebrovasc Dis. 2012;34(2):153-160.

2. Jovin TG, Chamorro A, Cobo E, de Miquel MA, Molina CA, Rovira A, San Roman L, et al. Thrombectomy within 8 hours after symptom onset in ischemic stroke. N Engl J Med. 2015;372(24):2296-2306.

3. Clua-Espuny JL, Ripolles-Vicente R, Forcadell-Arenas T, Gil-Guillen VF, Queralt-Tomas ML, GonzalezHenares MA, Panisello-Tafalla A, et al. Sex differences in long-term survival after a first stroke with intravenous thrombolysis: Ebrictus study. Cerebrovasc Dis Extra. 2015;5(3):95-102.

4. Audit Clinic de l'Ictus. Catalunya 2015. Pla Director de la omputer vascular cerebral. Sistema On Lined'Informacio de l'Ictusaguti Teleictus. Catalunya. 2014. (June, 8/2015). http://canalsalut.gencat.cat/web/.content/contingut_responsiu/salutAZ/I/ictus/prof/documents/arxius/InformeACI4CORR.pdf.

5. Eriksson M, Glader EL, Norrving B, Terent A, Stegmayr B. Sex differences in stroke care and outcome in the Swedish national quality register for stroke care. Stroke. 2009;40(3):909-914.

6. Forster A, Gass A, Kern R, Wolf ME, Ottomeyer C, Zoh- sel K, Hennerici M, et al. Gender differences in acute ischemic stroke: etiology, stroke patterns and response to thrombolysis. Stroke. 2009;40(7):2428-2432.

7. Lorenzano S, Ahmed N, Falcou A, Mikulik R, Tatlisumak T, Roffe C, Wahlgren N, et al. On behalf of the SITS Investigators. Does sex influence the response to intravenous thrombolysis in ischemic stroke? Stroke. 2013;44:340-3406.

8. Gargano JW, Reeves MJ, Paul Coverdell National Acute Stroke Registry Michigan Prototype I. Sex differences in stroke recovery and stroke-specific quality of life: results from a statewide stroke registry. Stroke. 2007;38(9):25412548.

9. Niewada M, Kobayashi A, Sandercock PA, Kaminski B, Czlonkowska A, International Stroke Trial Collaborative G. Influence of gender on baseline features and clinical outcomes among 17,370 patients with confirmed ischaemic stroke in the international stroke trial. Neuroepidemiology. 2005;24(3):123-128.

10. Kent DM, Buchan AM, Hill MD. The gender effect in stroke thrombolysis: of CASES, controls, and treatmenteffect modification. Neurology. 2008;71(14):1080-1083.

11. Meseguer E, Mazighi M, Labreuche J, Arnaiz C, Cabrejo L, Slaoui T, Guidoux C, et al. Outcomes of intravenous recombinant tissue plasminogen activator therapy according to gender: a clinical registry study and systematic review. Stroke. 2009;40(6):2104-2110.

12. Clua-Espuny JL, Ripolles-Vicente R, Lopez-Pablo C, Panisello-Tafalla A, Lucas-Noll J, Calduch-Noll C, Gonzalez-Henares MA, et al. [Differences in the survival after an episode of stroke treated with thrombolytic therapy. Study Ebrictus]. Aten Primaria. 2015;47(2):108-116.

13. Buijs JE, Uyttenboogaart M, Brouns R, de Keyser J, Kamphuisen PW, Luijckx GJ. The effect of age and sex on clinical outcome after intravenous recombinant tissue plasminogen activator treatment in patients with acute ischemic stroke. J Stroke Cerebrovasc Dis. 2016;25(2):312316.

14. Phan HT, Blizzard CL, Reeves MJ, Thrift AG, Cadilhac D, Sturm J, Heeley E, et al. Sex Differences in Long-Term Mortality After Stroke in the INSTRUCT (INternational STRoke oUtComes sTudy): A Meta-Analysis of Individual Participant Data. Circ Cardiovasc Qual Outcomes. 2017;10(2): e003436.

15. Clua-Espuny JL, Pinol-Moreso JL, Panisello-Tafalla A, Lucas-Noll J, Gil-Guillen VF, Orozco-Beltran D, Queralt-Tomas ML. Estudio Ebrictus. Resultados funcionales, supervivencia y anos potenciales de vida perdidos despues del primer episodio de ictus. Aten Primaria. 2012;44(4):223-231.

16. Clua-Espuny JL, Pinol-Moreso JL, Gil-Guillen JF, Orozco-Beltran D, Panisello-Tafalla A, Lucas-Noll J. La atencion sanitaria del ictus en el areaTerres de l'Ebre desde la implantacion del Codigo Ictus: Estudio Ebrictus. Med Clin. 2012;138:609-611.

17. Clua-Espuny JL, Garces-Redondo M, Lucas-Noll J, Panisello-Tafalla A, Queralt-Tomas ML. Stroke epidemiology, survival and disability in a Mediterranean population according Malmgren's Criteria. Ebrictus Cohort. Ann 
Vasc Med Res. 2014;1(1):1004.

18. Mehndiratta P, Wasay M, Mehndiratta MM. Implications of female sex on stroke risk factors, care, outcome and rehabilitation: an Asian perspective. Cerebrovasc Dis. 2015;39(5-6):302-308.

19. Hametner C, Ringleb P, Kellert L. Sex and hemisphere - a neglected, nature-determined relationship in acute ischemic stroke. Cerebrovasc Dis. 2015;40(1-2):59-66.

20. Queralt-Tomas ML, Panisello-Tafalla A, GonzalezHenares A, Clua-Espuny JL, Campo-Tamayo W, et al. Complex chronic patients and atrial fibrillation: association with cognitive deterioration and heart failure. J Clin Exp Res Cardiol. 2017;3(1):104.

21. Zupanic E, von Euler M, Kareholt I, Contreras Escamez B, Fastbom J, Norrving B, Religa D, et al. Thrombolysis in acute ischemic stroke in patients with dementia: A Swedish registry study. Neurology. 2017;89(18):18601868.

22. Clua-Espuny JL, Gonzalez-Henares MA, Queralt-Tomas MLL, Campo-Tamayo W, Muria-Subirats E, PaniselloTafalla A, Lucas-Noll J. Mortality and cardiovascular complications in older complex chronic patients with type 2 diabetes. Biomed Res Int. 2017;2017:6078498.

23. Van der Berg SA, Mulder MJHL, Goldhoorn RB, Coutinho JM, Roozenbeek B, Dippel DWJ, on behalf of the MR CLEAN Registry investigators. Blood pressure and functional outcome after endovascular treatment: Results from the MR CLEAN Registry. Large Clinical Trials 2. 4th European Stroke Organisation Conference, 16-18 May 2018/ Gothenburg, Sweden. https:/www.mrcleantrial.org/mr-clean-registry/introduction.html (accessed 20/05/2018).

24. Ishikawa H, Wakisaka $Y$, Matsuo R, Makihara N, Hata J, Kuroda J, Ago T, et al. Influence of Statin Pretreatment on Initial Neurological Severity and Short-Term Functional Outcome in Acute Ischemic Stroke Patients: The Fukuoka Stroke Registry. Cerebrovasc Dis. 2016;42(5-6):395-403.

25. Aboa-Eboule C, Binquet C, Jacquin A, Hervieu M, Bonithon-Kopp C, Durier J, Giroud M, et al. Effect of previous statin therapy on severity and outcome in ischemic stroke patients: a population-based study. J Neurol. 2013;260(1):30-37.

26. Ciccone A, Motto C, Aritzu E, Piana A, Candelise L. Negative interaction of aspirin and streptokinase in acute ischemic stroke: further analysis of the Multicenter Acute Stroke Trial-Italy. Cerebrovasc Dis. 2000;10(1):61-64.

27. Steffel J, Heidbuchel H. 'Ten Commandments' of the EHRA Guide for the Use of NOACs in AF. Eur Heart J. 2018;39(16):1322.

28. Nikneshan D, Raptis R, Pongmoragot J, Zhou L, Johnston SC, Saposnik G, Investigators of the Registry of the Canadian Stroke N, et al. Predicting clinical outcomes and response to thrombolysis in acute stroke patients with diabetes. Diabetes Care. 2013;36(7):2041-2047.

29. Reeves MJ, Vaidya RS, Fonarow GC, Liang L, Smith EE, Matulonis R, Olson DM, et al. Quality of care and outcomes in patients with diabetes hospitalized with ischemic stroke: findings from Get With the Guidelines-Stroke. Stroke. 2010;41(5):e409-417.

30. Simpson CR, Wilson C, Hannaford PC, Williams D. Evidence for age and sex differences in the secondary prevention of stroke in Scottish primary care. Stroke. 2005;36(8):1771-1775.

31. Ankolekar S, Rewell S, Howells DW, Bath PM. The influence of stroke risk factors and comorbidities on assessment of stroke therapies in humans and animals. Int J Stroke. 2012;7(5):386-397.

32. Flynn D, Nesbitt DJ, Ford GA, McMeekin P, Rodgers H, Price C, Kray C, et al. Development of a computerized decision aid for thrombolysis in acute stroke care. BMC Medical Informatics and Decision Making. 2015;15:6.

33. Khatri P, Hacke W, Fiehler J, Saver JL, Diener HC, Bendszus M, Bracard S, et al. State of acute endovascular therapy: report from the 12 th thrombolysis, thrombectomy, and acute stroke therapy conference. Stroke. 2015;46(6):1727-1734.

34. Alberts MJ, Ollenschleger MD, Nouh A. Dawn of a new era for stroke treatment: implications of the DAWN study for acute stroke care and stroke systems of care. Circulation. 2018;137(17):1767-1769.

35. Campbell BC, Mitchell PJ, Kleinig TJ, Dewey HM, Churilov L, Yassi N, Yan B, et al. Endovascular therapy for ischemic stroke with perfusion-imaging selection. N Engl J Med. 2015;372(11):1009-1018.

36. Mayank Goyal, Andrew M. Demchuk, Bijoy K. Menon, Muneer Eesa, Jeremy L. Rempel, John Thornton, et al. for the ESCAPE trial investigators randomized assessment of rapid endovascular treatment of ischemic stroke. N Engl J Med. 2015;372:1019-1030.

37. Saver JL, Goyal M, Bonafe A, Diener HC, Levy EI, Pereira VM, Albers GW, et al. Stent-retriever thrombectomy after intravenous t-PA vs. t-PA alone in stroke. N Engl J Med. 2015;372(24):2285-2295.

38. Diana Aguiar de Sousa, Rascha von Martial, Sonia Abilleira, Thomas Gattringer, Adam Kobayashi, Miquel Gallofre, Franz Fazekas, et al. Access to and delivery of acute ischaemic stroke treatments: A survey of national scientific societies and stroke experts in 44 European countries. Eur Stroke J. 2019;4(1):13-28.

39. The burden of Stroke in Europe report. King's College London for the Stroke Alliance for Europe (SAFE). Brussels, May 11th 2017. http://www.strokeeurope.eu/downloads/TheBurdenOfStrokeInEuropeReport.pdf (accessed 25/03/2018). 